\title{
BMJ Open Factors associated with peritraumatic stress symptoms among the frontline healthcare workers during the outbreak of COVID-19 in China
}

\author{
Xinye Qi, ${ }^{1,2}$ Jiahui Wang (D) , ${ }^{1,2}$ Jingjing Liu, ${ }^{1,2}$ Daniel Adjei Amporfro (D) , ${ }^{1,2}$ \\ Kexin Wang, ${ }^{1,2}$ Huan Liu (1) , ${ }^{1,2}$ Saleh Shah, ${ }^{1,2}$ Qunhong Wu (1) , ${ }^{1,2}$ Yanhua Hao ${ }^{1,2}$
}

To cite: Qi X, Wang J, Liu J, et al. Factors associated with peritraumatic stress symptoms among the frontline healthcare workers during the outbreak of COVID-19 in China. BMJ Open 2022;12:e047753. doi:10.1136/ bmjopen-2020-047753

- Prepublication history and additional supplemental material for this paper are available online. To view these files, please visit the journal online (http://dx.doi.org/10.1136/ bmjopen-2020-047753)

Received 08 December 2020 Accepted 13 December 2021

Check for updates

(c) Author(s) (or their employer(s)) 2022. Re-use permitted under CC BY-NC. No commercial re-use. See rights and permissions. Published by BMJ.

${ }^{1}$ Department of Health Policy, Health Management College, Harbin Medical University, Harbin, Heilongjiang, China ${ }^{2}$ Department of Social Medicine, School of Public Health, Harbin Medical University, Harbin, Heilongjiang, China

Correspondence to Professor Qunhong Wu; wuqunhong@163.com and Professor Yanhua Hao; hyhyjw@126.com

\section{ABSTRACT}

Objectives This study aimed to examine the prevalence of peritraumatic stress symptoms (PTSSs), perceived threat, social support and factors contributing to clinically significant PTSS among frontline COVID-19 healthcare workers (HCWs) in China.

Design and setting An online survey through selfadministered questionnaires was conducted from 18 February to 4 March 2020, during the outbreak of COVID-19.

Outcomes measures PTSS was assessed using the post-traumatic stress disorder (PTSD) self-rating scale. Demographic and socioeconomic characteristics, selfreported health, physical/psychological symptoms, perceived threat from frontline work and perceived social support were investigated. Multivariable line regression analysis distinguished factors associated with HCWs' PTSS scores.

Results A total of $676(58.1 \%)$ HCWs have shown clinically significant high levels of PTSS. Only 441 (37.9\%) self-reported good health. Most had physical symptom(s) (915 (78.7\%)), psychological symptom(s) (906 (77.9\%)), inability to vent emotions (284 (24.4\%)), emotional exhaustion (666 (57.3\%)) and $1037(89.2 \%)$ needed professional respect. Moreover, social support received was less than expected, and the receipt of psychological services/help scored the lowest (3.11 \pm 1.73$)$. Combined psychological and physical symptoms, difficulty in releasing tension and venting emotions timely, fear of infection, emotional exhaustion and depersonalisation are significantly associated with PTSS scores among frontline HCWs. Working $\geq 8$ hours, having the senior professional title, self-reported health, enjoying perfect protection and control measures, economic subsidy and control policy on reducing discriminatory practices are negatively correlated with PTSS scores.

Conclusions During the outbreak of COVID-19, frontline HCWs experienced clinically significant high levels of PTSS and heavy workload, and the emergency resulted in their inadequate psychosocial support. If this is left unchecked, HCWs have a higher risk of developing PTSD. Early detection, identification and person-directed, targeted multidisciplinary interventions should be undertaken to address various influencing factors. Comprehensive measures, including setting up emotional release channels, as well as providing psychological and social support intervention for HCWs globally, are highly recommended.
Strengths and limitations of this study

- Multivariate linear regression was conducted to analyse factors associated with peritraumatic stress symptom (PTSS) scores of frontline healthcare workers (HCWs).

- Physical/psychological symptoms, perceived threats of frontline work and achieved/anticipated social support were investigated online during 18 February to 4 March 2020, the hot phase of the COVID-19 outbreak in China.

- This was the first study to explore the gap between achieved and anticipated social support of frontline HCWs during the early stage of the COVID-19 outbreak.

- Potential limitations include: the cross-sectional design, which resulted in a limit on causal inference; non-validated questions, which made extrapolation difficult; online self-reporting instruments, which caused the inherent recall bias; and the time of assessment, instruments and methods, which may have contributed to this overestimation of the prevalence of post-traumatic stress disorder.

- Longitude studies monitoring PTSS rates and effective intervention are needed.

\section{INTRODUCTION}

In December 2019, ${ }^{1}$ a novel coronavirus named SARS-CoV-2, which is responsible for causing COVID-19, ${ }^{23}$ was detected in Wuhan, China. ${ }^{4}$ The National Health Commission (NHC) of China and the WHO reported that the confirmed cases in mainland China had increased to 72436 on 17 February 2020, including 1868 deaths. ${ }^{5}$ Subsequently, the pandemic escalated domestically and internationally with a frightening transmission speed. ${ }^{67}$ The WHO declared a Public Health Emergency of International Concern and a pandemic on 30 January $2020^{8}$ and 11 March $2020,{ }^{9}$ respectively. Facing the multiple sources of unpredictable and uncontrollable stress of healthcare systems (eg, management 
of critical medical situations, frequent witnessing of death, insufficient or inadequate personal protective equipment) at the peak of the COVID-19 pandemic, frontline healthcare workers (HCWs) were exposed to a high risk of infection because of close, frequent contact with infected patients, ${ }^{10}$ with the infection rate of HCWs $(2.10 \%)$ being dramatically higher than that of non-HCWs $(0.43 \%) .{ }^{11}$ Human-to-human transmission, ${ }^{712}$ high morbidity, potential fatality ${ }^{13}$ and no vaccine for COVID- $19^{14}$ may have magnified the HCWs' hazard perception of COVID-19 and experiences of severe psychological distress, including COVID-19-related acute stress responses. ${ }^{1516}$

Post-traumatic stress disorder (PTSD) is a stress-related mental disorder that develops after experiencing or witnessing life-threatening traumatic events. ${ }^{17}{ }^{18}$ It places a s ubstantial burden not only on individuals, affecting their relationships and jobs, ${ }^{19}$ but also on the society. ${ }^{20}$ Due to cautious considerations on the clinical diagnosis of PTSD, individuals who meet the cut-off point with high scores are considered to have clinically significant peritraumatic stress symptoms (PTSSs). ${ }^{21}$ PTSS rates range from $10 \%$ to about $20 \%{ }^{22}$ in HCWs working in emergency care settings, with even higher rates $(8 \%-30 \%)$ among intensive care unit staff. ${ }^{23}{ }^{24}$ Moreover, HCWs, especially those working on the frontline, have reported negative consequences since the outbreak of the COVID-19 pandemic. ${ }^{25-27}$ It is worth considering that during a pandemic, HCWs are exposed to physical and psychological stressors that may result in severe mental health outcomes. ${ }^{22}$ Lu et $a l^{28}$ indicated that more than $33.3 \%$ of HCWs caring for infected patients had developed significant stress symptoms during previous pandemics. The worldwide spread of COVID-19 has challenged the capacity and effective response of healthcare systems. ${ }^{29}$ Given the crucial role in responding to a pandemic, policymakers need empirical evidence to address the substantial issue of psychological distress and mental health of HCWs. ${ }^{30}$ It is, therefore, critical that concerns about mental health and systematic psychological adjustment of frontline HCWs' response to the COVID-19 outbreak should be highlighted. ${ }^{22} 3132$

Although most individuals prove resilient after exposure to a traumatic event, ${ }^{33}$ several risk factors may compromise adaptation effectiveness. Identifying risk factors affecting frontline HCWs with high levels of PTSS is crucial to high-risk groups and to establish specific intervention programmes. Previous research has demonstrated that HCWs experience a high degree of mental disorders, ${ }^{44}$ and that social support is a buffer factor between trauma and PTSS development. ${ }^{22}$

Burnout, which can be described as emotional, physical, psychological and spiritual exhaustion, can impact workers' sense of accomplishment. ${ }^{35}{ }^{36}$ SteudteSchmiedgen et al confirmed that feeling physically or mentally exhausted is associated with a higher prevalence of PTSSs. ${ }^{37}$ Chirico et al also confirmed that burnout resulted from emotional exhaustion $(8.0 \%)$ and depersonalisation $(35.9 \%){ }^{38}$ Consequences of burnout are poor quality of care, professional mistakes, reduced attention to individual protection procedures and increased risk of contagion in the workplace. ${ }^{38-40}$ Thus, it is necessary to analyse the relationship between high levels of PTSS and burnout in HCWs.

Consistently, evidence indicates that support (eg, from family, friends and supervisors/colleagues) is an important resilience factor against the development of PTSS. ${ }^{4142}$ Besides, in particular, clinical settings (eg, isolation), it often leads to subsequent decreased social support. ${ }^{22}$ Furthermore, in the context of disaster medicine with the lack of human and technical resources, HCWs could also develop acute stress disorders, potentially degenerating into chronic $\mathrm{PTSD}^{43}$; supportive resources buffer the relationship between occupational demands and psychological distress and are worthy of critical attention. ${ }^{44}$ Though organisational social support has been emphasised to fill the gap of social support (received vs. anticipated) during an outbreak, ${ }^{45}$ to the best of our knowledge, there are no studies that assess the gap between the social support anticipated and the actual support by the HCWs.

Delayed-onset PTSS reflects the worsening of symptoms over time due to stressors that occur after the traumatic event. ${ }^{46}$ A review inferred that evidence of quantitative and qualitative interventions to improve the mental health of frontline HCWs during or after disease epidemics and pandemics was lacking. ${ }^{47}$ Horesh and Brown ${ }^{48}$ and Søvold et $a t^{49}$ called for valuable data collection to inform highquality practice and policy as soon as possible. Greene $e t$ al pointed out that it was important to examine mental distress and identify risk factors among HCWs at different pandemic phases. $^{50}$ Furthermore, risk and protective factors, such as physical symptoms, ${ }^{51}$ of frontline HCWs with high levels of PTSS during pandemics are still understudied. ${ }^{29}{ }^{52}$ Moreover, the prevalence of peritraumatic distress, perceived threat from frontline work and perceived social support among frontline HCWs exposed to the outbreak in China were not fully reported. Consequently, we hypothesised that demographic and socioeconomic characteristics, self-reported health, physical or psychological symptoms, perceived threat from frontline work and perceived social support contributed to the occurrence of high levels of PTSS. This study aims to assess Chinese frontline HCWs' mental health to develop possible intervention strategies, with the goal of reducing HCWs' psychiatric burden in China and worldwide in future outbreaks of infectious diseases.

\section{METHODS}

\section{Study design and sample size}

This was a cross-sectional study performed via an online survey, which was run from 18 February ${ }^{53}$ (72436 cases) to $4 \mathrm{March}^{54}$ (80552 cases), 2020. The study commenced 8 weeks after the COVID-19 epidemic outbreak in Wuhan. ${ }^{7}$ The sampling period corresponded to the period that 
witnessed the highest surge of COVID-19 cases in China, ${ }^{55}$ that is, the highest vulnerability period after the great distress with 2055 laboratory-confirmed that over 3000 medical health workers in (Wuhan) Hubei province, ${ }^{56}$ across 476 hospitals. ${ }^{567}$

An online survey of $1389 \mathrm{HCWs}$ in the epicentre of Hubei province and other hospitals around China was conducted between 18 February and 4 March 2020. (1) PTSS, (2) demographic and socioeconomic characteristics, (3) peritraumatic distress, including self-reported health, four physical symptoms and 11 psychology symptoms, (4) perceived threat from frontline work and (5) perceived social support were investigated through a selfdesignated questionnaire.

The sample was obtained by recruiting HCWs working in hospitals (the eligibility criteria). An electronic version of the questionnaire was sent to all HCWs willing to participate in this survey. A quality control officer checked each returned questionnaire and deleted poor-quality responses. Of the initial 1391 HCW responses, 1389 questionnaires were included in the data analysis after removing invalid respondents.

\section{Data analysis}

The sample size was estimated on the needs of logistic regression analysis; hence, it was 10 times greater than the number of independent variables. The results of this study were generated through descriptive statistics and multivariate regression analysis. Descriptive statistical processes were applied to demographic and socioeconomic characteristics and social-psychological variables. Categorical variables were expressed by frequency and percentage (absolute values), and continuous variables were expressed as mean $\pm \mathrm{SD}$. The normal distributions of the continuous variables were verified using P-P plots and $\mathrm{K}-\mathrm{S}$ tests. Model fits were evaluated using the DurbinWatson test. We calculated the total scores $($ mean $\pm \mathrm{SD})$ of PTSS and determined the percentage of clinically significant PTSS according to the PTSS guidelines. Differences between the two categories of variables were compared by the independent single-sample t-test, and differences between three or more categories were analysed by $\chi^{2}$ test. Bivariate correlation analysis between continuous variables and PTSS scores. Statistics, including $F$ values, R2 changes $(\Delta R 2)$, standardised regression coefficients $(\beta)$ and $p$ values, in the regression model, were reported. To avoid omitting the important variables, less stringent selection criteria of univariate analysis were adopted. Those variables with $\mathrm{p} \leq 0.40$ were entered into the multivariate linear models for further exploration, with PTSS scores serving as dependent variables. The internal consistency of the items was checked by the Cronbach's alpha. The composite reliability (CR) and the explained average variance extracted (AVE) values were considered for convergent validity. ${ }^{58}$ All the statistical significance of all two-tailed tests was set at $\mathrm{p}<0.05$, and SPSS V.19 software was used for the statistical analysis.

\section{Dependent variable}

\section{Peritraumatic stress symptoms}

The PTSD self-rating scale (PTSD-SS) is a self-report measure developed by Chinese experts Liu et a $\tilde{p}^{9}$ that captures the level of symptomatic responses to a specific traumatic stressor, related to the consequent development of PTSD symptoms. The PTSD-SS matched well with the specific conditions of Chinese culture and lifestyle, and was proved to be a valid screening method to identify patients experiencing trauma in China. ${ }^{60}$

Theoretically, PTSD-SS can be divided into subjective assessments of traumatic events (item 1), repeated experiences (items 2, 3, 4, 5, 17, 18, 19), avoidance symptoms (items $6,8,9,10,16,21,22$ ), increased alertness (items 7 , $11,12,13,15,20,23$ ) and impaired social functioning (items $14,24)$. Based on the statement of the Diagnostic and Statistical Manual of Mental Disorders FourthEdition, ${ }^{61}$ regarding characteristics of PTSD and the PTSD response index scale, ${ }^{62}$ the diagnostic criteria of PTSD in International Classification of Diseases 11th Revision, ${ }^{63}$ and the diagnostic criteria of delayed stress disorder in The Chinese Classification of Mental Disorders, Second Edition, Revised, ${ }^{64}$ the PTSD-SS contains 24 items. These were developed to measure a set of characteristic symptoms (lasting for at least 1 month) that occurred after stress incidents, including persistent repetition of traumatic experiences, avoidance of events or situations related to traumatic events or general reaction numbness and heightened vigilance. Each item reflects the influence of traumatic events on physiology, psychology and life. ${ }^{6566}$

The scale has been shown to have high internal consistency, with a Cronbach's alpha within 0.921-0.965, ${ }^{59} 67-69$ good test-retest reliability and validity. Li et $a l^{70}$ showed that the internal consistency coefficient, the split-half reliability coefficient and the retest reliability coefficient of PTSD-SS were $0.9106,0.9217$ and 0.8547 , respectively. Huang et al reported that the content validity of PTSD-SS was 0.902, and the Cronbach's alpha was $0.939 .{ }^{71}$ Liu et al reported that the re-test correlation was $0.39(\mathrm{p}<0.01)$ and the Cronbach's alpha was within $0.745-0.878 .^{72}$ The pre-test conducted on 20 emergency department nurses and trauma patients had a Cronbach's alpha of $0.80^{65}$ and $0.66-0.88,{ }^{73}$ respectively. Therefore, PTSD-SS has good empirical validity and can be used as an assessment tool for PTSS scores. ${ }^{74}$

The scale contains 24 items and 3 subscales, namely, subjective assessment of intrusion, avoidance and hyperarousal. The degree of distress for each item is rated on a 5 -point scale ( $1=$ the absence of a symptom to $5=$ maximal symptoms). For symptoms of intrusion, avoidance and hyperarousal, scores of each subscale were calculated, and an average score above 2 was used as the cut-off value. A cut-off score of 50 on the PTSD-SS total score indicated a clinically significant high level of PTSS. The higher the score, the more severe the PTSS reaction. In this study, the Cronbach's alpha of the total scale and subscales were $0.974,0.951,0.941$ and 0.892 , respectively. The AVE and CR of the subscales were within 0.887-0.944 and 0.5660.663 , respectively. In this study, 'COVID-19 pandemic' 
and 'during the emergency' were respectively used for the subjects as a reference of a traumatic event and a specific time frame.

\section{Independent variable}

Independent variables included in the modelling were demographic and socioeconomic characteristics, peritraumatic distress, perceived threat from frontline work and perceived social support. Demographic and socioeconomic characteristics included age group $(1=20-30$ years, $2=30-40$ years, $3=>40$ years), gender $(1=$ male, $2=$ female $)$, profession (1=nurse, $2=$ physician, $3=$ medical technician, $4=$ administrator $)$, professional title ( $1=$ without professional title, 2=primary, $3=$ =intermediate, $4=$ senior) and working in a designated medical institution for COVID-19 treatment $(0=$ no, $1=$ yes $)$.

\section{Perceived peritraumatic distress}

The symptoms experienced for more than a month included physical and psychological symptoms. ${ }^{75}$ Physical symptoms comprised $^{76}$ : (1) palpitations, (2) discomfort or feeling of pressure in the chest, (3) headaches and (4) poor concentration. The Cronbach's alpha of the 4-item physical symptoms was 0.909 , and the $\mathrm{AVE}=0.685, \mathrm{CR}=0.896$. Psychological symptoms included $^{77}$ : (1) fear, (2) horror, (3) depression, (4) suspicion, (5) suppression, (6) helplessness, (7) no confidence, (8) irritability, (9) guilt, (10) solitariness and (11) frustration. Participants were asked to report if they had experienced these feelings during COVID-19 frontline work (eg, 'Having palpitations and worrying about heart trouble'). The Cronbach's alpha of the 11-item psychological symptoms was 0.973 , and the $\mathrm{AVE}=0.745, \mathrm{CR}=0.970$. More than one physical/psychological symptom of peritraumatic reaction could be endorsed. Each reported physical/ psychological symptom was rated on a 5-point Likert scale from 1 to 5 ( $5=$ strongly agree to $1=$ strongly disagree) and recoded into two categories: ' $0=$ no' or ' $1=$ yes' (rated score from 1 to 5) for the purpose of logistic regression modelling. The number of physical symptoms (maximum 4) and psychological symptoms (maximum 11) were added up to obtain the total score.

The Maslach Burnout Inventory (MBI) consisted of three subscales: emotional exhaustion (items 1, 2, 3, 6, 8, 13, 14, 16, 20), depersonalisation (items $5,10,11,15,22$ ) and personal accomplishment (items 4, 7, 9, 12, 17, 18, 19, 21). In this study, the Cronbach's alpha for each of the three dimensions was $0.936,0.859,0.877$, respectively; the total scale had good internal consistency (Cronbach's alpha $=0.900$ ).

A key question measured self-reported health, 'Please choose one point on this $0-100$ scale, which can best represent your health today; 0 means the worst and 100 means the best.' The responses were organised into two categories; ' $0=$ less than 80 ' and ' $1=$ more than 80 .' Additionally, sleep hours and working hours per day were reported by participants and classified into two categories: sleep hours per day (1=less than 6 hours, $2=$ more than 6 hours) and working hours per day (1=less than 8 hours, $2=$ more than 8 hours).

\section{Perceived threat of frontline work}

Participants also reported perceived threat from frontline work measured by self-designated questions ${ }^{78}$ : 'colleagues or relatives infected with COVID-19' ( $0=$ no and $1=y e s)$. Further, 'nowhere to release tension', 'the inability to vent emotions', 'guilt towards the family', 'the need for professional respect', 'feeling physically and mentally exhausted', all of them reported ranging from 1 (none) to 5 (very much).

\section{Perceived social support}

Future research should continue to understand the psychological well-being of HCWs who deal with infectious disease outbreaks and the effectiveness of intervention programmes. ${ }^{79} 80$ On 26 January 2020, the NHC published the 'Guiding Principles for the Emergency Psychological Crisis of the Novel Coronavirus Infection' ${ }^{81}$ On 10 February 2020, 'Notice on Several Measures for Improving the Working Conditions of Frontline Medical Staff and Taking Care of the Physical and Mental Health of Medical Staff' was also issued, which proposed more specific supports to improve the mental health of HCWs fighting with the COVID-19 outbreak. ${ }^{82}$

Therefore, participants were asked to rate the social support received and the social support demanded/ anticipated to cope with COVID-19 $9^{83-87}$ using a 6-point scale where $0=$ not at all, $1=$ very little, $2=$ little, $3=$ neutral, $4=$ much and $5=$ verymuch. We measured the supply of prevention and control materials, perfect protection and control measures, protection of rights and interests in pandemic prevention, support of providing more medical personnel to ease the existing overburdened staff, economic subsidy, support of providing a place to rest, support of providing psychological services and help, policy on discriminatory practices and security for the family. The Cronbach's alpha of actual received social support $(\mathrm{CR}=0.919, \mathrm{AVE}=0.558$, factor loading range within 0.689-0.804) and demanded/anticipated social support $(\mathrm{CR}=0.912, \mathrm{AVE}=0.537$, factor loading range within $0.603-0.784$ ) were $0.900,0.891$, respectively. The difference in each type of social support related to COVID-19 frontline work between the actually received and demanded/anticipated was calculated and sorted into three categories: $1=$ the actual support gained is less than the demanded/anticipated, $2=$ the actual support achieved is equal to the demanded/anticipated and $3=$ the actual support is greater than the demanded/anticipated.

\section{Patient and public involvement statement}

There was no patient or public involvement in the production of this study.

\section{RESULTS}

\section{Bivariate analyses}

\section{Demographic/socioeconomic characteristics}

An analysis of statistics revealed that 1163 (83.7\%) participants reported working in frontline positions during the COVID-19 pandemic (online supplemental etable 
Table 1 Comparison of PTSS scores among different demographic/socioeconomic characteristics in frontline HCWs fighting against COVID-19 $(n=1163)$

\begin{tabular}{|c|c|c|c|c|}
\hline & & PTSS scores & & \\
\hline & $n^{*}(\%)$ & $\mathrm{M} \pm \mathrm{SD}$ & Test statistic & $P$ value \\
\hline Total & 1163 & $57.17 \pm 21.49$ & & \\
\hline PTSS & & & - & - \\
\hline No & $487(41.9)$ & $36.33 \pm 8.55$ & & \\
\hline Yes (clinical significant, $\geq 50$ ) & $676(58.1)$ & $72.18 \pm 14.28$ & & \\
\hline Sext & & & 1.998 & 0.158 \\
\hline Male & $322(27.7)$ & $55.73 \pm 21.43$ & & \\
\hline Female & $841(72.3)$ & $57.72 \pm 21.51$ & & \\
\hline Ageł & & & 3.788 & 0.023 \\
\hline $20-30$ & $384(33.0)$ & $59.02 \pm 21.61$ & & \\
\hline $31-40$ & $506(43.5)$ & $57.28 \pm 21.24$ & & \\
\hline $41+$ & $273(23.5)$ & $54.36 \pm 21.58$ & & \\
\hline Professional title§ & & & 5.260 & 0.022 \\
\hline Without professional title & $56(4.8)$ & $58.89 \pm 20.933$ & & \\
\hline Primary & $556(47.8)$ & $57.75 \pm 21.49$ & & \\
\hline Intermediate & 351 (30.2) & $58.47 \pm 21.75$ & & \\
\hline Senior & $200(17.2)$ & $52.81 \pm 20.816$ & & \\
\hline Profession§ & & & 0.745 & 0.863 \\
\hline Nurse & $642(55.2)$ & $57.43 \pm 21.43$ & & \\
\hline Physician & $314(27.0)$ & $57.53 \pm 20.86$ & & \\
\hline Medical technician & $125(10.7)$ & $55.02 \pm 22.15$ & & \\
\hline Administrator & $82(7.1)$ & $57.09 \pm 23.55$ & & \\
\hline Working in designated medical institutions for COVID-19 treatment $†$ & & & 12.994 & $<0.001$ \\
\hline No & $309(26.6)$ & $53.41 \pm 19.48$ & & \\
\hline Yes & $854(73.4)$ & $57.17 \pm 21.49$ & & \\
\hline Colleagues or relatives infected with COVID-19† & & & 18.012 & $<0.001$ \\
\hline No & $937(80.6)$ & $55.94 \pm 21.52$ & & \\
\hline Yes & $226(19.4)$ & $62.27 \pm 20.67$ & & \\
\hline Sleep hours per day & & & 9.483 & 0.002 \\
\hline Inadequate (less than 6 hours) & $657(56.5)$ & $58.87 \pm 22.12$ & & \\
\hline Adequate (more than 6 hours) & $506(43.5)$ & $54.97 \pm 20.47$ & & \\
\hline Work hours per day & & & 0.832 & 0.362 \\
\hline Less than 8 hours & $840(72.2)$ & $56.82 \pm 21.47$ & & \\
\hline More than 8 hours & $323(27.8)$ & $58.08 \pm 21.57$ & & \\
\hline
\end{tabular}

Categorical variables displayed as $\mathrm{n}(\%)$, continuous variables displayed as mean $\pm \mathrm{SD}$.

${ }^{*}$ Number of each group; $p$ values are two-tailed.

tt-test for independent group.

$\ddagger$ Pearson $r$ correlation.

$\S$ Analysis of variance.

HCWs, healthcare workers; PTSS, peritraumatic stress symptom.

1). Participants' characteristics are listed in table 1 and online supplemental etable 2. Of the total number of participants (1163), $676 \quad(58.1 \%)$ experienced clinically significant PTSS. The majority of the respondents $(72.3 \%)$ were women, and the median age was $35.75 \pm 8.52$. Most (43.5\%) of the participants were aged 31-40 years. Nurses comprised $55.2 \%$ of the study population, followed by physicians $(27.0 \%)$ and medical technicians $(10.7 \%)$. Among the respondents, without professional title, primary, intermediate and senior titles accounted for $4.8 \%, 47.8 \%, 30.2 \%$ and $17.2 \%$, respectively. Of the participants, $56.5 \%$ reported sleeping less than 6 hours 
Table 2 Results of univariate ANOVAs and t-tests showing mean differences on PTSS scores based on personal factors

\begin{tabular}{|c|c|c|c|}
\hline & \multicolumn{3}{|c|}{ PTSS scores } \\
\hline & Mean \pm SD & $r / t$ & P value \\
\hline Self-reported health (maximum 100)* & $73.42 \pm 19.59$ & -0.399 & $<0.001$ \\
\hline Personal accomplishment (maximum score is 30 points) ${ }^{*}$ & $29.63 \pm 10.08$ & -0.019 & 0.525 \\
\hline Depersonalisation (maximum score is 48 points)* & $8.05 \pm 6.64$ & 0.575 & $<0.001$ \\
\hline Number of psychological symptoms (maximum 4)* & $6.29 \pm 4.63$ & 0.697 & $<0.001$ \\
\hline
\end{tabular}

*Pearson $r$ correlation.

ANOVA, analysis of variance; PTSS, peritraumatic stress symptom.

per day, $27.8 \%$ reported work more than 8 hours per day, $226(19.4 \%)$ reported that their colleagues or relatives were infected with COVID-19 and $854(73.4 \%)$ reported working in designated medical institutions for COVID-19 treatment. The mean score of PTSS was 57.17 \pm 21.49 . The subscale of PTSS scores was $32.60 \pm 11.71,15.65 \pm 6.88$ and $8.93 \pm 3.92$ for intrusion, avoidance and hyperarousal, respectively. Meanwhile, PTSS scores were significantly different in the frontline HCWs groups (eg, age, professional title, working in designated medical institutions for COVID-19 treatment, colleagues or relatives infected with COVID-19, sleep hours per day and so on). Frontline HCWs who reported sleeping less than 6 hours $(p=0.002)$, colleagues or relatives infected with COVID-19 $(\mathrm{p}<0.001)$ and working in designated medical institutions for COVID-19 treatment $(\mathrm{p}<0.001)$ showed higher PTSS scores than those who had not.

Furthermore, $78.7 \%$ of the frontline HCWs reported at least one physical symptom, $786(67.6 \%)$ having palpitations, 741 (63.7\%) having discomfort or feeling pressure in the chest, $754(64.8 \%)$ having headaches or pressure and $753(64.7 \%)$ having poor concentration (online supplemental efigures 1and 2).

Peritraumatic distress: self-reported health, physical/psychological symptoms and burnout

Moreover, the average number of physical symptoms and psychological symptoms was $2.61 \pm 1.65$ and $6.29 \pm 4.63$, respectively (table 2 ). The average score of self-reported health was $73.42 \pm 19.59$, and $37.9 \%$ of the frontline HCWs self-reported good health. The self-reported health $(\mathrm{r}=-0.399, \mathrm{p}<0.001)$, emotional exhaustion $(\mathrm{r}=0.663$, $\mathrm{p}<0.001)$, depersonalisation $(\mathrm{r}=0.575, \mathrm{p}<0.001)$, number of physical symptoms $(r=0.609, p<0.001)$ and number of psychological symptoms $(\mathrm{r}=0.697, \mathrm{p}<0.001)$ were significantly associated with PTSS scores.

Furthermore, $234(20.1 \%)$ reported nowhere to release tension, $284(24.4 \%)$ reported inability to vent emotions, $665(57.2 \%)$ reported feeling guilty towards the family for being unable to take care of family members due to work, $1037(89.2 \%)$ reported the need for professional respect and 417 (35.9\%) reported physical and mental exhaustion, while $57.3 \%$ reported emotional exhaustion measured by the MBI scales (online supplemental etable $3)$. Meanwhile, participants reported $6.29 \pm 4.63$ psychological symptoms and $2.61 \pm 1.65$ physical symptoms.

\section{Perceived threat from frontline work and perceived demanded social support}

Table 3 presents perceived threat from working at the frontline and perceived social support related to frontline HCWs. The correlation analysis results showed that nowhere to release tension $(\mathrm{r}=0.540, \mathrm{p}<0.001)$, disability to vent emotions $(\mathrm{r}=0.517, \mathrm{p}<0.001)$, feeling guilt towards the family $(\mathrm{r}=0.243, \mathrm{p}<0.001)$, the need for professional respect $(\mathrm{r}=-0.084, \mathrm{p}=0.004)$ and fear of infected $(r=0.377$, $\mathrm{p}<0.001$ ) were significantly associated with PTSS scores.

Moreover, 'supply of prevention and control materials $(\mathrm{r}=0.094, \mathrm{p}=0.001)$ ', 'protection of rights and interests in pandemic prevention $(\mathrm{r}=0.079, \mathrm{p}=0.007)$ ', 'more medical personnel to ease the existing overburdened staff $(\mathrm{r}=0.106, \mathrm{p}<0.001)$ ', 'economic subsidy $(\mathrm{r}=0.060$, $\mathrm{p}=0.041)$ ', 'support of providing a place to rest $(\mathrm{r}=0.112$, $\mathrm{p}<0.001$ )', 'support of providing psychological services and help $(r=0.270, p<0.001)$ ' and 'security for the family $(\mathrm{r}=0.082, \mathrm{p}=005)$ ' were significantly associated with PTSS scores.

The actual perceived supply of all social support related to COVID-19 frontline HCWs is lower than its actual demanded/anticipated (figure 1). Support of providing psychological service and help was reported as the lowest actual perceived and actual demanded/ anticipated. Furthermore, frontline HCWs reported the highest proportion of the need for a policy on discriminatory HCWs practices $(77.9 \%)$ and security for the family $(77.7 \%$ ) (online supplemental efigure 3). Moreover, frontline HCWs reported significant differences in the actual received and actual demanded/anticipated of 'supply of prevention and control materials', 'protection and control measures', 'protection of rights and interests in epidemic prevention', 'more medical personnel to ease the existing overburdened staff', 'economic subsidy', 'support of providing a place to rest', 'support of providing psychological services and help', 'policy on discriminatory practices' and 'security for the family' $(\mathrm{p}<0.05$, online supplemental efigure 4$)$. 
Table 3 Bivariate associations between perceived threat from frontline work and perceived demanded/anticipated social support with PTSS scores

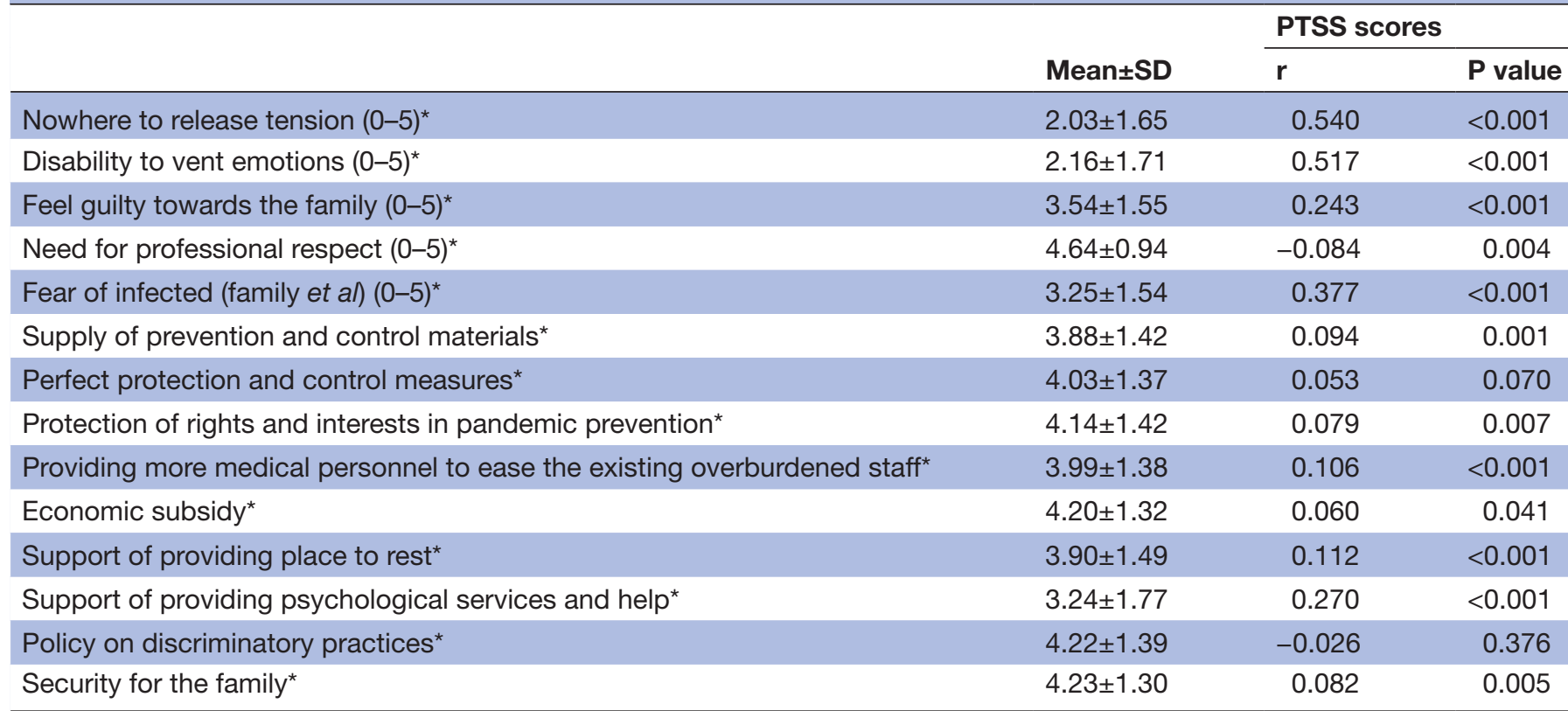

*Pearson r correlation.

PTSS, peritraumatic stress symptom.

\section{Multivariate analyses}

The results of the multivariate linear regression analysis on the influencing factors associated with PTSS scores in frontline HCWs fighting against COVID-19 are shown in table 4. Number of psychological symptoms $(\beta=0.278$, $\mathrm{p}<0.001)$, number of physical symptoms $(\beta=0.108$, $p<0.001)$, emotional exhaustion $(\beta=0.239, \quad p<0.001)$, depersonalisation $(\beta=0.071, p=0.010)$, severity perception degree of 'nowhere to release tension' $(\beta=0.113$, $\mathrm{p}<0.001)$, 'disability to vent emotions' $(\beta=0.069, \mathrm{p}=0.009)$ and 'fear of infected' $(\beta=0.095, p<0.001)$ were significantly associated with higher PTSS scores.
Frontline HCWs who worked more than 8 hours $(\beta=-0.090, p<0.001)$ and with the senior professional title $(\beta=-0.114, p=0.003)$ were significantly associated with lower PTSS scores. In addition, self-reported health $(\beta=-0.077, \quad \mathrm{p}<0.001)$, perfect protection and control measures $(\beta=-0.057, \quad p=0.048)$, economic subsidy $(\beta=-0.064, p=0.011)$ and policy on reducing discriminatory practices $(\beta=-0.063, \mathrm{p}=0.006)$ were also significantly correlated with lower PTSS scores. Together, these 13 variables explained $63.3 \%$ of the variance in the outcome measures.

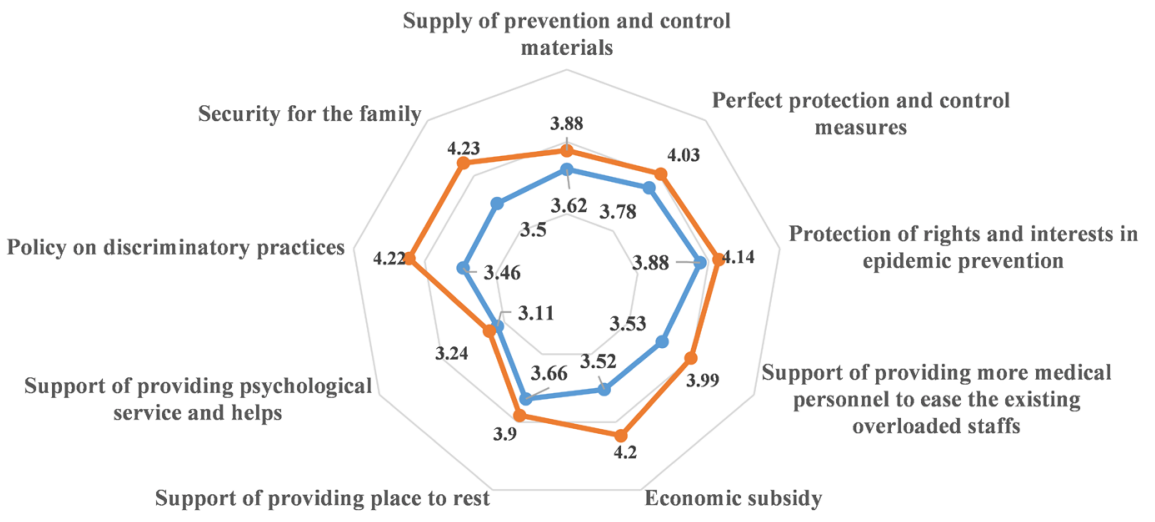

$\longrightarrow$ Actual received social support $\quad \longrightarrow$ Actual demanded/anticipated social support

Figure 1 Scores of actual perceived social support and demanded/anticipated social support. 
Table 4 Multivariate linear regression analysis on influencing factors associated with PTSS scores in frontline HCWs fighting against COVID-19

\begin{tabular}{|lllllll}
\hline Variable & $\mathbf{B ~ ( 9 5 \% \text { Cl) }}$ & SE & $\boldsymbol{\beta}$ & $\mathbf{t}$ & P value & VIF \\
\hline Constant & $45.793(37.023$ to 54.563$)$ & 4.470 & & & & \\
Gender & $0.826(-0.974$ to 2.626$)$ & 0.918 & 0.017 & 0.900 & 0.368 & 1.119 \\
Age (vs 20-30) & & & & & & \\
$\quad 31-40$ & $0.240(-1.769$ to 2.249$)$ & 1.024 & 0.006 & 0.234 & 0.815 & 1.720 \\
\hline $1+$ & $2.237(-0.735$ to 5.209$)$ & 1.515 & 0.044 & 1.477 & 0.140 & 2.775 \\
\hline
\end{tabular}

Professional title (vs without professional

title)

\begin{tabular}{|c|c|c|c|c|c|c|}
\hline Primary & $-2.958(-6.698$ to 0.783$)$ & 1.906 & -0.068 & -1.551 & 0.121 & 6.045 \\
\hline Intermediate & $-2.788(-6.709$ to 1.133$)$ & 1.998 & -0.059 & -1.395 & 0.163 & 5.643 \\
\hline Senior & $-6.511(-10.867$ to 2.156$)$ & 2.220 & -0.114 & -2.933 & 0.003 & 4.721 \\
\hline $\begin{array}{l}\text { Working in designated medical institutions } \\
\text { for COVID-19 treatment }\end{array}$ & $0.440(-1.354$ to 2.234$)$ & 0.915 & 0.009 & 0.481 & 0.631 & 1.087 \\
\hline Sleep hours per day (vs $<6$ hours) & $-0.357(-1.996$ to 1.281$)$ & 0.835 & -0.008 & -0.428 & 0.669 & 1.142 \\
\hline Work hours per day (vs < 8 hours) & $-4.402(-6.293$ to 2.511$)$ & 0.964 & -0.090 & -4.568 & 0.000 & 1.199 \\
\hline $\begin{array}{l}\text { Colleagues or relatives infected with } \\
\text { COVID-19 }\end{array}$ & $-1.606(-3.628$ to 0.416$)$ & 1.030 & -0.030 & -1.558 & 0.119 & 1.123 \\
\hline Self-reported health & $-0.084(-0.129$ to 0.040$)$ & 0.023 & -0.077 & -3.693 & 0.000 & 1.351 \\
\hline Number of psychological symptoms & 1.296 (0.993 to 1.599$)$ & 0.154 & 0.278 & 8.389 & 0.000 & 3.402 \\
\hline Number of physical symptoms & 1.412 (0.654 to 2.170$)$ & 0.386 & 0.108 & 3.654 & 0.000 & 2.695 \\
\hline Nowhere to release tension & 1.479 (0.797 to 2.160$)$ & 0.347 & 0.113 & 4.259 & 0.000 & 2.193 \\
\hline Disability to vent emotions & $0.866(0.215$ to 1.517$)$ & 0.332 & 0.069 & 2.612 & 0.009 & 2.143 \\
\hline Feel guilty towards the family & $-0.250(-1.978$ to 1.478$)$ & 0.881 & -0.006 & -0.284 & 0.776 & 1.266 \\
\hline Need for professional respect & $-0.754(-1.640$ to 0.133$)$ & 0.452 & -0.033 & -1.667 & 0.096 & 1.218 \\
\hline The fear of infected & $1.337(0.746$ to 1.927$)$ & 0.301 & 0.095 & 4.443 & 0.000 & 1.419 \\
\hline Emotional exhaustion & 0.394 (0.292 to 0.495$)$ & 0.052 & 0.239 & 7.623 & 0.000 & 3.046 \\
\hline Depersonalisation & 0.231 (0.055 to 0.408$)$ & 0.090 & 0.071 & 2.569 & 0.010 & 2.378 \\
\hline $\begin{array}{l}\text { Supply of prevention and control materials } \\
\text { (demanded) }\end{array}$ & $0.275(-0.546$ to 1.097$)$ & 0.419 & 0.018 & 0.658 & 0.511 & 2.359 \\
\hline $\begin{array}{l}\text { Perfect protection and control measures } \\
\text { (demanded) }\end{array}$ & $-0.893(-1.778$ to 0.007$)$ & 0.451 & -0.057 & -1.978 & 0.048 & 2.577 \\
\hline $\begin{array}{l}\text { Protection of rights and interests in } \\
\text { pandemic prevention (demanded) }\end{array}$ & $0.334(-0.433$ to 1.102$)$ & 0.391 & 0.022 & 0.855 & 0.393 & 2.079 \\
\hline $\begin{array}{l}\text { Providing more medical personnel to ease } \\
\text { the existing overburdened staff (demanded) }\end{array}$ & $-0.070(-0.851$ to 0.711$)$ & 0.398 & -0.004 & -0.176 & 0.860 & 2.028 \\
\hline Economic subsidy (demanded) & $-1.049(-1.860$ to 0.237$)$ & 0.414 & -0.064 & -2.536 & 0.011 & 1.972 \\
\hline $\begin{array}{l}\text { Support of providing place to rest } \\
\text { (demanded) }\end{array}$ & $0.699(-0.024$ to 1.422$)$ & 0.368 & 0.048 & 1.896 & 0.058 & 2.023 \\
\hline $\begin{array}{l}\text { Support of providing psychological services } \\
\text { and help (demanded) }\end{array}$ & $0.528(-0.016$ to 1.072$)$ & 0.277 & 0.043 & 1.904 & 0.057 & 1.603 \\
\hline $\begin{array}{l}\text { Policy on discriminatory practices } \\
\text { (demanded) }\end{array}$ & $-0.969(-1.652$ to 0.285$)$ & 0.348 & -0.063 & -2.780 & 0.006 & 1.588 \\
\hline Security for the family (demanded) & $0.679(-0.166$ to 1.525$)$ & 0.431 & 0.041 & 1.577 & 0.115 & 2.096 \\
\hline
\end{tabular}

Durbin-Watson=1.978; R2=0.643, Adjusted R2=0.633, $F=68.781, p<0.001$.

Variance inflation factor $<10$.

$B$, regression coefficient; HCWs, healthcare workers; PTSS, peritraumatic stress symptom; VIF, variance inflation factor; $\beta$, standardised regression coefficient. 


\section{DISCUSSION}

A meta-analysis confirmed that HCWs exposed to frequently witnessing death and trauma are particularly at risk of PTSS. ${ }^{22}$ Our results reflected the immediate psychological responses of frontline HCWs to the early stage of the COVID-19 outbreak in China. The prevalence of clinically significant high levels of PTSS among frontline HCWs was $58.1 \%$; the average score of PTSS was $57.17 \pm 21.49$. The PTSS in this study is more serious than a cross-sectional study launched in a tertiary infectious disease hospital $(27.89 \%, 42.92 \pm 17.88),{ }^{69}$ indicating that a considerable proportion of the frontline HCWs suffered with high levels of PTSS themselves during their provision of life-saving care service to others in the early stage of the COVID-19 outbreak. The current study provides empirical evidence for the short-term peritraumatic effects of the COVID-19 pandemic and related factors, which can help to guide targeted care and multiple-intervention mental health services (eg, regular screening, early intervention, design prevent strategies) within practices for reducing the risk of high levels of PTSS and managing the psychological impact on frontline HCWs during the pandemic.

There is increasing evidence that PTSD is comorbid with mental and physical symptoms. ${ }^{88}$ Our results showed that frontline HCWs reported several physical symptoms $(2.61 \pm 1.65)$ and psychological symptoms (6.29 \pm 4.63$)$, indicating that frontline HCWs in the early stage of the COVID-19 outbreak faced serious health conditions. Specifically, frontline HCWs with more physical or psychological symptoms reported higher PTSS scores. However, a vicious circle involving immunosuppression between COVID-19 and PTSS was revealed. ${ }^{89}$ The immune mechanism is closely related to physical and psychological health, ${ }^{90}$ and stress can weaken the immune system ${ }^{91}$ or precipitate or worsen specific physical symptoms ${ }^{92}$ such as cardiovascular, respiratory, neurological or gastrointestinal symptoms. ${ }^{93}$ Meanwhile, acute psychological stress can activate the sympathetic adrenal medulla system and the hypothalamus-pituitary-adrenal axis, and this two-component stress response impacts on physical and mental health and can contribute to diseases. ${ }^{94}$ Once the immune balance breaks, frontline HCWs are directly exposed to considerable risks. Our results revealed that frontline HCWs tolerated excruciating psychological symptoms (ie, $68.8 \%$ experienced fear, $66.6 \%$ grief and $63.5 \%$ helplessness), and most frontline HCWs reported palpitations (67.6\%) and headaches (64.8\%). However, physical symptoms (ie, headaches, palpitations) during the COVID-19 outbreak may be over-represented due to psychological stress, ${ }^{93}$ which may reflect vulnerability to PTSD and compromise HCWs' resilience after being exposed to a traumatic event. ${ }^{22}$ Due to the delayed appearance and inconspicuous nature of PTSSs, ${ }^{95}$ it is essential to monitor these regularly to diagnose and intervene timely and prevent the development of PTSS during the COVID-19 pandemic. ${ }^{96}$ In this study, compared with the self-reported poor health group, the self-reported good health group had a lower PTSS score. Therefore, it is crucial not to neglect such physical symptoms as they may reflect underlying psychological distress. ${ }^{97}$ Interestingly, we also found that longer daily work hours were associated with a higher risk of depressive symptoms and PTSD. An overload of work frequently imposes both physical and psychological strains on the medical staff; and the PTSS scores illustrate the importance of reasonable work arrangements for the mental health of the medical staff. ${ }^{98}$ Targeted multidisciplinary interventions addressing psychological and physical symptoms are needed to support HCWs.

HCWs' burnout has a significant impact on the wellness and productivity of physicians, as well as on patient health outcomes. The overall pooled prevalence of burnout symptoms among nurses globally was $11.23 \% .^{99}$ A recent study reported that more than $40 \%$ of frontline nurses during the COVID-19 pandemic might experience burnout. ${ }^{100}$ In this study, $57.3 \%$ of the frontline HCWs reported emotional exhaustion, while only $35.9 \%$ of them perceived the threat of being physically and mentally exhausted (self-reported), indicating severe job burnout, a general lack of awareness and low concern among frontline HCWs. Our results showed that more emotional exhaustion and depersonalisation were positively related to the high PTSS score. Frontline HCWs with medium to high emotional exhaustion reported $57.3 \%$ of clinically significant PTSS, respectively. Ruotsalainen et $a l$ and Salyers et al proved that effective interventions could reduce emotional exhaustion and suggested a more active stress management policy in healthcare institutions. ${ }^{101}{ }^{102}$ In this study, $55.5 \%$ of frontline HCWs reported perceived psychological service and help. Therefore, two points need attention: burnout feelings of frontline HCWs are the manifestation of fatigue and disease precursors. Notably, early detection, identification and person-directed and organisational interventions, such as incentives or insurance guaranteed by the government are essential during this pandemic.

Based on the buffering hypothesis/moderator effect model, ${ }^{103}$ social support is a beneficial factor in reducing the perception of threats, and it acts as an important environmental resource in confronting adverse situations. ${ }^{104}$ Austin et al confirmed that disproportionate social support has implications for physical health. ${ }^{105}$ In this study, the actually achieved social support and needed social support were mismatched, which is not consistent with $\mathrm{Li}$ et al $\mathrm{s}^{106}$ findings that the individual's need for support matches the type of support provided during the COVID-19 pandemic.

As frontline HCWs may underestimate their demand for psychological service, it creates the illusion that their needs are met. Our results indicated that actual perceived support of receiving perceived support from psychological service had the lowest score $(3.11 \pm 1.37)$ among all perceived types of social support, and the selfreported need for psychological service and help was only $3.24 \pm 1.77$. Frontline HCWs focused on the social support 
from the policy for discrimination and wounded HCWs $(77.9 \%)$, security for the family $(77.7 \%)$, economic subsidy $(77.1 \%)$ and protection of rights and interests in pandemic prevention $(76.4 \%)$. A meta-analysis of controlled studies involving single-session debriefing after trauma aimed at preventing the development of PTSS failed to show that the intervention was effective. ${ }^{107}$ Although psychological assistance services, including telephone, internet and application-based counselling or intervention, have been widely deployed by local and national mental health institutions in response to the COVID-19 pandemic, ${ }^{108-110}$ psychological intervention services were problematic. Chen et $a l^{25}$ reported that medical staff was reluctant to participate in the group or individual psychological interventions. Indeed, frontline HCWs may have been overwhelmed by the emotional impact of the situation.

This 'matching hypothesis' suggests that to satisfy the expectations of perceived support, the provider's actions must meet the specific needs of the recipient, and social support interventions may only be beneficial if the recipient's support needs are not already being met. ${ }^{111}$ In this study, higher PTSS scores were associated with low perfect protection and control measures, which is consistent with Muller $e t a l$ s suggestion that HCWs are more interested in occupational protection and rest than professional psychological help. ${ }^{42}$ Frontline HCWs who reported a severe degree of having nowhere to release stress $(20.1 \%)$ or an inability to vent emotions (24.4\%) reported a higher PTSS score than those who did not. Studies have confirmed that people who have suffered traumatic events need to alleviate their emotions timely to prevent the generation of negative emotions. ${ }^{112}{ }^{113}$ However, despite the suffocating pressure, frontline HCWs may deliberately suppress emotions due to the sense of responsibility or the desire for professional respect. Problems in the provision of psychological counselling services include psychiatrists who are not willing to provide face-to-face mental health services to other HCWs who are identified as a fragile population in the COVID-19 outbreak, ${ }^{114}$ and HCWs who report reluctancy in receiving psychological intervention services (eg, due to lack of time or motivation). ${ }^{22}{ }^{25}$ Supporting healthcare professionals through psychological services or counselling enables them to become aware of their emotions and remain efficient and focused during these stressful times. Financial stress and legal involvement due to trauma have been addressed in the risks of PTSS. ${ }^{115}$ Therefore, and based on 'the Stanford Medicine Hear me, Protect me, Prepare me, Support me, Care for me' model, ${ }^{116}$ tangible assistance and effective psychological intervention conducted by multi-agents (eg, organisation, work term, psychiatrist) are needed to explore the flexible demands of psychological support aiming to deal with the serious mental health issues of frontline HCWs involved in the COVID-19 pandemic. ${ }^{117}$

In the ongoing COVID-19 pandemic, the lack of personal protection devices represents a critical issue. ${ }^{22}$ Out of the participating HCWs, $36.8 \%$ perceived that the supply of prevention and control materials was less than the demand, and $47.5 \%$ described dissatisfaction with the hospital's protective measures. Frontline HCWs perceived mismatches to requirements and acquisition of specific social support. Previous studies have shown that perceived threat is an essential predictor of PTSS. ${ }^{22}$ Meanwhile, burnout (eg, emotional exhaustion, depersonalisation) was a contributing factor to the higher PTSS score. ${ }^{118}$ As workers may misidentify traumatic symptoms (eg, arousal, detachment) as burnout rather than a traumatic response referring to PTSS, ${ }^{119}$ it is necessary to distinguish between PTSS and burnout of HCWs. Workplace health programmes and health surveillance for protecting the mental health of HCWs are needed. ${ }^{40}$ Among individuals diagnosed with PTSD, men and women are similar in phenotypic expression, ${ }^{120}$ and we found that males and females have no difference in PTSS scores. In this study, frontline HCWs with family members or close relatives infected with COVID-19 were not significantly related to PTSS scores. This is consistent with 'the Psychological Typhoon Eye' effect, indicating that repeated exposure to a catastrophic environment can increase an individual's level of resilience and improve their ability to resist adverse life events. Therefore, mental health-related factors should be taken into account in the selection of frontier-line medical staff. ${ }^{121}$ Overall, early comprehensive, extensive longitudinal detection and interventions are essential to rebuild resilient organisations and rapidly reconfigure the well-being priorities to deal with drivers of stress. ${ }^{116}$

\section{Limitations and recommendation}

There are some limitations to our study. First, as it is a cross-sectional study, the relationships between variables were only correlative. Causal relationships could not be established, and evidence from the longitudinal or experimental study should be employed further. Second, the results depended on respondents' online self-reporting instruments, and non-validated questions were used; these are potential sources of biases, and recall bias is inherent in the survey. Results of this study should be interpreted with caution because many of the psychosocial measures analysed were not from validated survey instruments. Third, a strict application of the diagnostic criteria is essential in research on PTSD. PTSD-SS cannot be used as a substitute for full clinical diagnostic criteria or for addressing the conceptual diagnostic problems and designing research to resolve diagnostic uncertainties empirically. ${ }^{122}$ Qualitative face-to-face interviews to obtain the true inner experience of frontline HCWs are needed. Fourth, frontline HCWs willing to be investigated were included in the study, so there is a bias. Fifth, the study was conducted within a month of the COVID-19 outbreak, which was the peak of the rescue operation and might be time sensitivity assessed PTSS scores, including exposure to numerous potentially traumatic stressors to frontline HCWs. Due to the continuous progress of the pandemic, HCWs' mental health symptoms may have 
fluctuated. It is not yet known whether the mental state of frontline personnel will recover. Therefore, long-term psychological implications on this population are worth further investigation.

\section{CONCLUSION}

The prevalence of clinically significant high levels of PTSS, peritraumatic distress and inadequate psychosocial support during the hot phase of the COVID-19 outbreak in China was high among Chinese frontline HCWs. Overall, frontline HCWs experienced physical and psychological burdens, felt they had nowhere to release tension and an inability to vent emotions, reported one or more physical/ psychological symptoms, and felt the stress of insufficient medical supplies at hospitals. Protecting HCWs is an essential component of public health measures to address the COVID-19 pandemic. As HCWs have had a shortage globally, effective and empirical psychological intervention conducted by multi-agents (eg, organisation, work term, psychiatrist) is needed to explore the flexibility demands of psychological support and develop clear pathways to constant effective psychological care for dealing with the serious mental health issues of frontline HCWs involved in the COVID-19 pandemic.

Contributors $\mathrm{XQ}$ contributed to writing; $\mathrm{XQ}, \mathrm{QW}$ and $\mathrm{JL}$ contributed to conceptualisation and methodology; JW, HL and KW contributed to investigation; YH contributed to project administration; $\mathrm{QW}$ and $\mathrm{YH}$ contributed to funding acquisition and supervision; DAA and SS contributed to review and editing. QW is the author acting as guarantor.

Funding The National Social Science Fund of China (Grant No.19AZD013); National Natural Science Foundation of China (Grant No. 72042001).

Competing interests None declared.

Patient consent for publication Consent obtained directly from patient(s).

Ethics approval This study involves human participants and was approved by the Committee on the Ethics of Harbin Medical University (HMUIRB20200003). Moreover, informed consent was obtained from each participant before the start of work. All voluntary participants gave their informed consent with the assurance of confidentiality and anonymity of the data, according to ethical principles for medical research involving human subjects. The question 'Do you agree to participate in this survey' was asked to acquire the consent of the participants and only the 'Yes' option led to the next page for the questionnaires. Once completed, the questionnaire could be submitted only once to prevent duplication. This study was conducted by the ethical standards of the Declaration of Helsinki (2008). Participants were invited personally by the investigator, and they were asked to participate voluntarily with a full right to withdraw from the study. The database used in this study contains identification data used to protect the privacy of participants. Participants gave informed consent to participate in the study before taking part.

Provenance and peer review Not commissioned; externally peer reviewed.

Data availability statement Data are available upon reasonable request.

Supplemental material This content has been supplied by the author(s). It has not been vetted by BMJ Publishing Group Limited (BMJ) and may not have been peer-reviewed. Any opinions or recommendations discussed are solely those of the author(s) and are not endorsed by BMJ. BMJ disclaims all liability and responsibility arising from any reliance placed on the content. Where the content includes any translated material, BMJ does not warrant the accuracy and reliability of the translations (including but not limited to local regulations, clinical guidelines, terminology, drug names and drug dosages), and is not responsible for any error and/or omissions arising from translation and adaptation or otherwise.

Open access This is an open access article distributed in accordance with the Creative Commons Attribution Non Commercial (CC BY-NC 4.0) license, which permits others to distribute, remix, adapt, build upon this work non-commercially, and license their derivative works on different terms, provided the original work is properly cited, appropriate credit is given, any changes made indicated, and the use is non-commercial. See: http://creativecommons.org/licenses/by-nc/4.0/.

\section{ORCID iDs}

Jiahui Wang http://orcid.org/0000-0002-6869-8164

Daniel Adjei Amporfro http://orcid.org/0000-0003-4842-4171

Huan Liu http://orcid.org/0000-0002-1882-1160

Qunhong Wu http://orcid.org/0000-0002-2873-5266

\section{REFERENCES}

1 Zhu N, Zhang D, Wang W, et al. A novel coronavirus from patients with pneumonia in China, 2019. N Engl J Med 2020;382:727-33.

2 Coronaviridae Study Group of the International Committee on Taxonomy of Viruses. The species severe acute respiratory syndrome-related coronavirus: classifying $2019-\mathrm{nCoV}$ and naming it SARS-CoV-2. Nat Microbiol 2020;5:536-44.

3 WHO Director-General's remarks at the media briefing on 2019nCoV, 2020. Available: https://www.who.int/dg/speeches/detail/ who-director-general-s-remarks-at-the-media-briefing-on-2019ncov-on-11-february-2020 [Accessed 6 Oct 2020].

4 Huang C, Wang Y, Li X, et al. Clinical features of patients infected with 2019 novel coronavirus in Wuhan, China. Lancet 2020;395:497-506.

5 The National Health Commission of China. Updates on the novel coronavirus outbreak up to February 17, 2020. Updates on the novel coronavirus outbreak up to February 17, 2020. Available: http://www.nhc.gov.cn/xcs/yqtb/202002/261f72a74be14c4db6e1 b582133cf4b7.shtml [Accessed 6 Oct 2020].

6 Munster VJ, Koopmans M, van Doremalen N, et al. A novel coronavirus emerging in China - key questions for impact assessment. N Engl J Med Overseas Ed 2020;382:692-4.

$7 \mathrm{Li} \mathrm{Q}$, Guan X, Wu P, et al. Early transmission dynamics in Wuhan, China, of novel coronavirus-infected pneumonia. N Engl J Med 2020;382:1199-207.

8 Statement on the second meeting of the International Health Regulations. Emergency Committee regarding the outbreak of novel coronavirus (2019-nCoV), 2005. Available: https://www. who.int/news-room/detail/30-01-2020-statement-on-the-secondmeeting-of-the-international-health-regulations-(2005)-emergencycommittee-regarding-the-outbreak-of-novel-coronavirus-(2019ncov) [Accessed 6 Oct 2020].

9 WHO Director-General's opening remarks at the media briefing on COVID-19, 2020. Available: https://www.who.int/dg/speeches/ detail/who-director-general-s-opening-remarks-at-the-mediabriefing-on-covid-19-11-march-2020 [Accessed 24 Sep 2020].

10 Shih F-J, Gau M-L, Kao C-C, et al. Dying and caring on the edge: Taiwan's surviving nurses' reflections on taking care of patients with severe acute respiratory syndrome. Appl Nurs Res 2007;20:171-80.

11 Zheng L, Wang X, Zhou C. Analysis of the infection status of the health care workers in Wuhan during the COVID-19 outbreak: a cross-sectional study. Clin Infect Dis.

12 Rothe C, Schunk M, Sothmann P, et al. Transmission of 2019-nCoV infection from an asymptomatic contact in Germany. N Engl J Med 2020;382:970-1.

13 Wang W, Tang J, Wei F. Updated understanding of the outbreak of 2019 novel coronavirus (2019-nCoV) in Wuhan, China. J Med Virol 2020;92:441-7.

14 The Vaccine Tracker, 2020. Available: https://github.com/ thevaccinetracker/thevaccinetracker [Accessed 24 Sep 2020].

15 Bao Y, Sun Y, Meng S, et al. 2019-nCoV epidemic: address mental health care to empower Society. Lancet 2020;395:e37-8.

16 Holman EA, Thompson RR, Garfin DR. The unfolding COVID-19 pandemic: a probability-based, nationally representative study of mental health in the United States. Sci Adv 2020;6:eabd5390.

17 Wu KK, Chan SK, Ma TM. Posttraumatic stress, anxiety, and depression in survivors of severe acute respiratory syndrome (SARS). J Trauma Stress 2005;18:39-42.

18 Bryant RA, Creamer M, O'Donnell M, et al. Acute and chronic posttraumatic stress symptoms in the emergence of posttraumatic stress disorder: a network analysis. JAMA Psychiatry 2017;74:135-42.

19 Michigan Medicine. Posttraumatic stress disorder during COVID-19, 2020. Available: https://medicine.umich.edu/dept/psychiatry/ michigan-psychiatry-resources-covid-19/specific-mental-health- 
conditions/posttraumatic-stress-disorder-during-covid-19 [Accessed 6 Oct 2020].

20 Kessler RC. Posttraumatic stress disorder: the burden to the individual and to Society. J Clin Psychiatry 2000;61:4-12.

21 Zhou Y, Sun Z, Wang Y, et al. The prevalence of PTSS under the influence of public health emergencies in last two decades: a systematic review and meta-analysis. Clin Psychol Rev 2021;83:101938.

22 Carmassi C, Foghi C, Dell'Oste V, et al. PTSD symptoms in healthcare workers facing the three coronavirus outbreaks: what can we expect after the COVID-19 pandemic. Psychiatry Res 2020;292:113312.

23 Poncet MC, Toullic P, Papazian L, et al. Burnout syndrome in critica care nursing staff. Am J Respir Crit Care Med 2007;175:698-704.

24 Mealer M, Burnham EL, Goode CJ, et al. The prevalence and impact of post traumatic stress disorder and burnout syndrome in nurses. Depress Anxiety 2009;26:1118-26.

25 Chen Q, Liang M, Li Y, et al. Mental health care for medical staff in China during the COVID-19 outbreak. Lancet Psychiatry 2020;7:e15-16.

26 Du J, Dong L, Wang T. Psychological symptoms among frontline healthcare workers during COVID-19 outbreak in Wuhan. Gen Hosp Psychiatry.

27 Lai J, Ma S, Wang Y, et al. Factors associated with mental health outcomes among health care workers exposed to coronavirus disease 2019. JAMA Netw Open 2020;3:e203976.

28 Lu Y-C, Shu B-C, Chang Y-Y, et al. The mental health of hospital workers dealing with severe acute respiratory syndrome. Psychother Psychosom 2006;75:370-5.

29 Preti E, Di Mattei V, Perego G, et al. The psychological impact of epidemic and pandemic outbreaks on healthcare workers: rapid review of the evidence. Curr Psychiatry Rep 2020;22:43.

$30 \mathrm{WHO}$. Rapid reviews to strengthen health policy and systems: a practical guide. Available: http://www.who.int/alliance-hpsr/ resources/publications/rapid-review-guide/en/ [Accessed 14 Oct $2020]$.

31 Zaka A, Shamloo SE, Fiorente P, et al. COVID-19 pandemic as a watershed moment: a call for systematic psychological health care for frontline medical staff. J Health Psychol 2020;25:883-7.

32 Salazar de Pablo G, Vaquerizo-Serrano J, Catalan A, et al. Impact of coronavirus syndromes on physical and mental health of health care workers: systematic review and meta-analysis. J Affect Disord 2020;275:48-57.

33 Bonanno GA, Galea S, Bucciarelli A, et al. What predicts psychological resilience after disaster? The role of demographics, resources, and life stress. J Consult Clin Psychol 2007;75:671-82.

34 Zhang W-R, Wang K, Yin L, et al. Mental health and psychosocial problems of medical health workers during the COVID-19 epidemic in China. Psychother Psychosom 2020;89:242-50.

35 Cummings C, Singer J, Hisaka R, et al. Compassion satisfaction to combat work-related burnout, vicarious trauma, and secondary traumatic stress. J Interpers Violence 2021;36:NP5304-19.

36 Chirico F, Crescenzo P, Sacco A, et al. Prevalence of burnout syndrome among Italian volunteers of the red cross: a crosssectional study. Ind Health 2021;59:117-27.

37 Steudte-Schmiedgen S, Stieler L, Erim Y, et al. Correlates and predictors of PTSD symptoms among healthcare workers during the COVID-19 pandemic: results of the egePan-VOICE study. Front Psychiatry 2021;12:686667.

38 Chirico F. [Is burnout a syndrome or an occupational disease? Instructions for occupational physicians]. Epidemiol Prev 2017:41:294-8.

39 d'Ettorre G, Ceccarelli G, Santinelli L, et al. Post-traumatic stress symptoms in healthcare workers dealing with the COVID-19 pandemic: a systematic review. Int J Environ Res Public Health 2021;18:601.

40 Chirico F, Nucera G, Magnavita N. Protecting the mental health of healthcare workers during the COVID-19 emergency. BJPsych Int:1-2.

41 Chan AOM, Huak CY. Psychological impact of the 2003 severe acute respiratory syndrome outbreak on health care workers in a medium size regional General Hospital in Singapore. Occup Med 2004;54:190-6.

42 Muller AE, Hafstad EV, Himmels JPW, et al. The mental health impact of the covid-19 pandemic on healthcare workers, and interventions to help them: a rapid systematic review. Psychiatry Res 2020;293:113441.

43 Dutheil F, Mondillon L, Navel V. PTSD as the second tsunami of the SARS-Cov-2 pandemic. Psychol Med 2020:1-2.

44 Alizadeh A, Khankeh HR, Barati M, et al. Psychological distress among Iranian health-care providers exposed to coronavirus disease 2019 (COVID-19): a qualitative study. BMC Psychiatry 2020;20:494.

45 Sirois FM, Owens J. Factors associated with psychological distress in health-care workers during an infectious disease outbreak: a rapid systematic review of the evidence. Front Psychiatry 2020;11:589545.

46 Galatzer-Levy IR, Huang SH, Bonanno GA. Trajectories of resilience and dysfunction following potential trauma: a review and statistical evaluation. Clin Psychol Rev 2018;63:41-55.

47 Pollock A, Campbell P, Cheyne J, et al. Interventions to support the resilience and mental health of frontline health and social care professionals during and after a disease outbreak, epidemic or pandemic: a mixed methods systematic review. Cochrane Database Syst Rev 2020;11:CD013779.

48 Horesh D, Brown AD. Traumatic stress in the age of COVID-19: a call to close critical gaps and adapt to new realities. Psychological Trauma: Theory, Research, Practice, and Policy;12:331-5.

49 Søvold LE, Naslund JA, Kousoulis AA, et al. Prioritizing the mental health and well-being of healthcare workers: an urgent global public health priority. Front Public Health 2021:9:679397.

50 Greene T, Harju-Seppänen J, Adeniji M, et al. Predictors and rates of PTSD, depression and anxiety in UK frontline health and social care workers during COVID-19. Eur J Psychotraumatol 2021;12:1882781.

51 Chew NWS, Lee GKH, Tan BYQ, et al. A multinational, multicentre study on the psychological outcomes and associated physical symptoms amongst healthcare workers during COVID-19 outbreak. Brain Behav Immun 2020;88:559-65.

52 Dong Z-Q, Ma J, Hao Y-N, et al. The social psychological impact of the COVID-19 pandemic on medical staff in China: a crosssectional study. Eur Psychiatry 2020;63:e65.

53 The latest situation of the new coronavirus pneumonia epidemic as of 24:00 on February 17. Available: http://www.nhc.gov.cn/ xcs/yqtb/202002/261f72a74be14c4db6e1b582133cf4b7.shtml [Accessed 29 Jul 2021].

54 The latest situation of the novel coronavirus pneumonia epidemic as of 24:00 on March 5. Available: http://www.nhc.gov.cn/xcs/yqtb/ 202003/b59dbcc84ed1498292714975039dcdc9.shtml [Accessed 29 Jul 2021].

55 The latest situation of the novel coronavirus pneumonia epidemic as of 24:00 on February 12. Available: http://www.nhc.gov.cn/xcs/ yqtb/202002/26fb16805f024382bff1de80c918368f.shtml [Accessed 29 Jul 2021].

56 Guangming Online. Central steering group: over 3,000 medical staff in Hubei were infected in the early stage of the epidemic, currently no infection reports among medical aid staff. Available: https:// politics.gmw.cn/2020-03/06/content_33626862.htm [Accessed 29 Jul 2021].

57 National Health Commission of the People's Republic of China China-WHO joint investigation report of Covid-19. Available: http:// www.nhc.gov.cn/jkj/s3578/202002/87fd92510d094e4b9bad5976 08f5cc2c.shtml [Accessed 28 Jul 2021].

58 Alarcón D, Sánchez JA. Assessing convergent and discriminant validity in the ADHD-R IV rating scale: user-written commands for average variance extracted (AVE), composite reliability (CR), and Heterotrait-Monotrait ratio of correlations (HTMT);39.

59 Liu X, Liu L, Zhao G. [Development of the post-traumatic stress disorder self-rating scale and its reliability and validity]. Shandong Journal of Psychiatry1998;11.

60 Hong C, Efferth T. Systematic review on post-traumatic stress disorder among survivors of the Wenchuan earthquake. Trauma Violence Abuse 2016;17:542-61.

61 American Psychiatric Association. Diagnostic and statistical manual of mental disorders: DSM-IV; includes ICD-9-CM codes effective. Washington, DC, 1998.

62 Pynoos RS, Frederick C, Nader K, et al. Life threat and posttraumatic stress in school-age children. Arch Gen Psychiatry 1987;44:1057-63.

63 Fan X. ICD-10 mental and behavioral disorder classification clinical description and diagnosis essentials. Beijing: People's Medical Publishing House, 1993. http://book.ucdrs.superlib.net/views/ specific/2929/bookDetail.jsp?dxNumber=000000382115\&d=906A 9DCB071ED91275A9D2828584A7E7\&fenlei=161302

64 Chinese Society of Psychiatry. Chinese mental illness classification scheme and diagnostic criteria CCMD-2-R. Nanjing: Southeast University Press, 1995. http://book.ucdrs.superlib.net/views/ specific/2929/bookDetail.jsp?dxNumber=000006351327\&d=729F 48F189D8E0B4602206BA9E80C37B\&fenlei=161302

65 Lin L, Wu Y, He P. Research on post-traumatic stress disorder related to occupation and coping style in emergency nurses. J Nurs Sci 2009;24:3-5. 
66 Chinese Medical Psychiatric Branch. CCMD-3 Chinese classification and diagnostic criteria for mental disorders, 2001. Available: http://book.ucdrs.superlib.net/views/specific/2929/ bookDetail.jsp?dxNumber $=161000118213 \& d=5298 D E 65 C D 30$ CCA16922CFB439039B77\&fenlei= [Accessed 3 Jul 2021].

67 Shi X, Wang S, Wang Z, et al. The resilience scale: factorial structure, reliability, validity, and parenting-related factors among disaster-exposed adolescents. BMC Psychiatry 2021;21:145.

68 Zheng Y, Fan F, Liu X, et al. Life events, coping, and posttraumatic stress symptoms among Chinese adolescents exposed to 2008 Wenchuan earthquake, China. PLoS One 2012;7:e29404.

69 Huang JZ, Han MF, Luo TD, et al. [Mental health survey of medical staff in a tertiary infectious disease hospital for COVID-19]. Zhonghua Lao Dong Wei Sheng Zhi Ye Bing Za Zhi 2020;38:192-5.

$70 \mathrm{Li}, \mathrm{Qi}$ W. R evise of PTSD - SS in flight Crew group and its R eliability and validity. China J Health Psychol 2015;23:1536-9.

71 Huang, Huang Het al. Analysis of post-traumatic stress disorder status and influencing factors in patients with uremia. Anhui Med $J$ 2018;39:60-3.

72 Liu W, Fan F, Zhou C. Post-Traumatic stress symptoms among bereaved parents in severely damaged earthquake area: a 2-year follow-up study. Chinese Mental Health Journal 2012;26:252-6.

73 Zhang Y. The analysis and strategies on affecting the hospital discharge willingness by the psychological status of the Medicare trauma patients 2013.

74 Hou W. Prevalence and related factors of posttraumatic stress disorder symptoms in intensive care unit nurses, 2017. Available: https://kns.cnki.net $/ \mathrm{kcms} /$ detail/detail.aspx?filename $=1017857684$ nh\&dbcode $=$ CMFD\&dbname $=$ CMFD2018\& $v=x \| l m s M 5 R r A 6 R s h Y Y$ 8nk3DEbPsHEzHUKoQWro5LORgJ0Zepb1J3Z7bli7nQytngr6 [Accessed 3 Jul 2021].

75 Wang C, Pan R, Wan X, et al. A longitudinal study on the mental health of general population during the COVID-19 epidemic in China. Brain Behav Immun 2020;87:40-8.

76 Leinweber J, Creedy DK, Rowe $\mathrm{H}$, et al. A socioecological model of posttraumatic stress among Australian midwives. Midwifery 2017:45:7-13.

77 Si M-Y, Su X-Y, Jiang Y, et al. Psychological impact of COVID-19 on medical care workers in China. Infect Dis Poverty 2020;9:113.

78 Zwiebach L, Rhodes J, Roemer L. Resource loss, resource gain, and mental health among survivors of Hurricane Katrina: resource change and Posthurricane distress. J Traum Stress 2010;23:751-8.

79 Asaoka H, Koido Y, Kawashima Y, et al. Post-traumatic stress symptoms among medical rescue workers exposed to COVID-19 in Japan. Psychiatry Clin Neurosci 2020;74:503-5.

$80 \mathrm{Li} \mathrm{X}, \mathrm{Li} \mathrm{S}$, Xiang M. The prevalence and risk factors of PTSD symptoms among medical assistance workers during the COVID-19 pandemic. J Psychosom Res 2020;139:110270.

81 Notice on Issuing the guiding principles for emergency psychological crisis intervention in the novel coronavirus infected pneumonia epidemic. Available: http://www.nhc.gov.cn/jkj/s3577/ 202001/6adc08b966594253b2b791be5c3b9467.shtml [Accessed 7 Jul 2021].

82 The General Office of the State Council forwards the Notice of the National Health Commission, the Ministry of Human Resources and Social Security, and the Ministry of Finance on Several Measures to Improve the Working Conditions of Frontline Medical Staff and Caring for the Physical and Mental Health of Medical Staff (Guobanfa [2020] No. 4)_Government Information Disclosure Column. Available: http://www.gov.cn/zhengce/content/2020-02/ 11/content 5477399.htm [Accessed 7 Jul 2021].

83 Joob B, Wiwanitkit V. Traumatization in medical staff helping with COVID-19 control. Brain Behav Immun 2020;87:10

84 Wiwanitkit V. Support for health-care professionals during Wuhan coronavirus infection outbreak. Med J DY Patil Vidyapeeth 2020;13:187.

85 Guiding Opinions of the National Health Commission, the Ministry of Human Resources and Social Security, and the Ministry of Finance on Establishing a Long-term Mechanism for the Protection and Care of Medical Workers. Available: http://www.gov.cn/ zhengce/zhengceku/2021-05/12/content_5605977.htm [Accessed 7 Jul 2021].

86 Notice on strengthening psychological assistance and social work services in response to the new crown pneumonia epidemic. Available: http://www.nhc.gov.cn/jkj/s3577/202003/a9b0bcb3bb74 45298c480c5003c51d6d.shtml [Accessed 7 Jul 2021]

87 WHO Health Organization. Mental health and psychosocial considerations during the COVID-19 outbreak, 2020. Available: https://apps.who.int/iris/handle/10665/331490 [Accessed 2 Aug 2021].
88 Prout TA, Zilcha-Mano S, Aafjes-van Doorn K, et al. Identifying predictors of psychological distress during COVID-19: a machine learning approach. Front Psychol 2020;11:586202.

89 Liang X, Zhu Y, Fang Y. COVID-19 and post-traumatic stress disorder: a vicious circle involving immunosuppression. CNS Neurosci Ther 2020;26:876-8.

90 Hostinar CE, Nusslock R, Miller GE. Future directions in the study of early-life stress and physical and emotional health: implications of the neuroimmune network hypothesis. J Clin Child Adolesc Psychol 2018:47:142-56.

91 Stress weakens the immune system. Available: https://www.apa. org. https://www.apa.org/research/action/immune [Accessed 7 Oct 2020].

92 Puri BK, Hall A, Ho R. Revision notes in psychiatry. 3rd edn. Boca Raton, FL: CRC Press, 2014

93 McFarlane AC, Atchison M, Rafalowicz E. Physical symptoms in post-traumatic stress disorder. J Psychosom Res 1994;38:715-26.

94 Turner Al, Smyth N, Hall SJ, et al. Psychological stress reactivity and future health and disease outcomes: a systematic review of prospective evidence. Psychoneuroendocrinology 2020;114:104599

95 Frieden TR, Tappero JW, Dowell SF, et al. Safer countries through global health security. Lancet 2014;383:764-6.

96 Roberts T, Daniels J, Hulme W, et al. Psychological distress and trauma in doctors providing frontline care during the COVID-19 pandemic in the United Kingdom and Ireland: a prospective longitudinal survey cohort study. BMJ Open 2021;11:e049680.

97 Lam MH-B, Wing Y-K, Yu MW-M, et al. Mental morbidities and chronic fatigue in severe acute respiratory syndrome survivors: long-term follow-up. Arch Intern Med 2009;169:2142-7.

98 Song X, Fu W, Liu X, et al. Mental health status of medical staff in emergency departments during the coronavirus disease 2019 epidemic in China. Brain Behav Immun 2020;88:60-5.

99 Woo T, Ho R, Tang A, et al. Global prevalence of burnout symptoms among nurses: a systematic review and meta-analysis. J Psychiatr Res 2020;123:9-20.

100 Matsuo T, Kobayashi D, Taki F, et al. Prevalence of health care worker burnout during the coronavirus disease 2019 (COVID-19) pandemic in Japan. JAMA Netw Open 2020;3:e2017271.

101 Ruotsalainen J, Serra C, Marine A, et al. Systematic review of interventions for reducing occupational stress in health care workers. Scand J Work Environ Health 2008;34:169-78.

102 Salyers MP, Bonfils KA, Luther L, et al. The relationship between professional burnout and quality and safety in healthcare: a metaanalysis. J Gen Intern Med 2017;32:475-82.

103 Cohen S, Wills TA. Stress, social support, and the buffering hypothesis. Psychol Bull 1985;98:310-57.

104 Mattos AIS, Araújo TMde, Almeida MMGde. Interaction between demand-control and social support in the occurrence of common mental disorders. Rev Saude Publica 2017;51:48

105 Austin MK, Drage JN, Dezil J, et al. The relationship between disproportionate social support and metabolic and inflammatory markers: Moderating role of socioeconomic context. Psychosom Med 2021;83:177-86.

106 Li F, Luo S, Mu W, et al. Effects of sources of social support and resilience on the mental health of different age groups during the COVID-19 pandemic. BMC Psychiatry 2021;21:16.

107 van Emmerik AAP, Kamphuis JH, Hulsbosch AM, et al. Single session debriefing after psychological trauma: a meta-analysis. Lancet 2002;360:766-71.

108 Notice on the comprehensive implementation of several measures to further protect and care for medical personnel. Available: http:// www.gov.cn/zhengce/content/2020-02/23/content_5482345.htm [Accessed 23 Sep 2020].

109 The State Council of China. A notification to set up nationwide psychological assistance hotlines against the 2019-nCoV outbreak. A notification to set up nationwide psychological assistance hotlines against the 2019-nCoV outbreak. Available: http://www. gov.cn/xinwen/2020-02/02/content_5473937.htm [Accessed 6 Oct 2020].

110 General Office of the State Council of China. Key measures on improving the working conditions of frontline healthcare workers: caring for the physical and mental health of healthcare workers. Key measures on improving the working conditions of frontline healthcare workers: caring for the physical and mental health of healthcare workers. Available: http://www.gov.cn/zhengce/ content/2020-02/11/content_5477399.htm [Accessed 19 Sep 2020].

111 Melrose KL, Brown GDA, Wood AM. When is received social support related to perceived support and well-being? when it is needed. Pers Individ Dif 2015;77:97-105. 
112 Charuvastra A, Cloitre M. Social bonds and posttraumatic stress disorder. Annu Rev Psychol 2008;59:301-28.

113 Center for Substance Abuse Treatment (US). Trauma-informed care in behavioral health services. substance abuse and mental health services administration (US) 2014 https://www.ncbi.nlm.nih.gov/ books/NBK207191/

114 Shariati B, Eftekhar Ardebili M, Shalbafan M. Working in the emergency and inpatient COVID-19 special wards: a different experience for Iranian psychiatric trainees amid the outbreak. Asian J Psychiatr 2020;51:102157.

115 Sareen J. Posttraumatic stress disorder in adults: impact, comorbidity, risk factors, and treatment. Can J Psychiatry 2014;59:460-7.

116 Caring for health care workers during crisis: creating a resilient organization 2020;10.

117 Taylor SE. Social support: a review. Oxford University Press, 2011.
118 Li D, Wang Y, Yu H, et al. Occupational burnout among frontline health professionals in a high-risk area during the COVID-19 outbreak: a structural equation model. Front Psychiatry 2021:12:575005.

119 Waegemakers Schiff J, Lane AM. PTSD symptoms, vicarious traumatization, and burnout in front line workers in the homeless sector. Community Ment Health J 2019;55:454-62.

120 Kimerling R, Allen MC, Duncan LE. Chromosomes to social contexts: sex and gender differences in PTSD. Curr Psychiatry Rep 2018;20:114.

121 An Y, Sun Y, Liu Z, et al. Investigation of the mental health status of frontier-line and non-frontier-line medical staff during a stress period. J Affect Disord 2021;282:836-9.

122 Asmundson GJG, Taylor S. Garbage in, garbage out: the tenuous state of research on PTSD in the context of the COVID-19 pandemic and infodemic. J Anxiety Disord 2021;78:102368. 